\title{
O PAPEL DE NOVA FRIBURGO NA REDE DE LOCALIDADES CENTRAIS FLUMINENSE: UMA ANÁLISE COMPARATIVA 1966-2007 ${ }^{12}$ \\ THE ROLE OF NOVA FRIBURGO IN THE NETWORK OF CENTRAL FLUMINENSE LOCATIONS: A COMPARATIVE ANALYSIS 1966-2007
}

\author{
Miguel Angelo Campos Ribeiro ${ }^{1}$ \\ ${ }^{1}$ Universidade do Estado do Rio de Janeiro (UERJ), Rio de Janeiro, RJ, Brasil

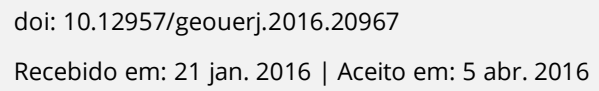

\section{RESUMO}

O artigo propõe-se a descrever e analisar as áreas de atuação das cidades fluminenses sob o comando de Nova Friburgo, Centro Sub-regional A. Tal estudo tornou-se pertinente em decorrência das transformações desencadeadas nos últimos quarenta anos no espaço fluminense, que de certa forma contribuíram para uma modificação na centralidade e no redimensionamento dos fluxos de deslocamentos de consumidores em busca de bens e serviços. Como procedimento operacional, a pesquisa realizada pautou-se na análise da Rede de Distribuição de Bens e Serviços, a partir da metodologia elaborada pela Coordenação de Geografia (CGEO) do IBGE, segundo as obras Divisão do Brasil em regiões funcionais urbanas - 1972 e Regiões de influência das cidades - 2007. A partir dessa metodologia foram elaborados quadros, mapas e esquemas, a saber: (1) níveis de centralidade/região de influência de Nova Friburgo 1966/2007; (2) hierarquia urbana de Nova Friburgo $1966 / 2007$

Palavras-chave: Rede urbana; níveis de centralidade; região de influência; Nova Friburgo.

\begin{abstract}
This article aims to describe and analyze the areas of influence of Rio de Janeiro cities under the umbrella of Nova Friburgo - Sub-regional Centre A. The relevance of the present study stems from the changes that have taken place in Rio de Janeiro over the last forty years, which have contributed in a way to change the centrality and size of consumer travel flows motivated by the search for goods and services. As an operational procedure, this study conducted an analysis of the Goods and Services Distribution Network, based on the methodology developed by the Coordination of Geography (CGEO) of IBGE and in accordance with the studies The Breakdown of Brazil into Functional Urban Regions (1972) and Regions of Influence of Cities (2007). Based on this methodology, tables, maps and diagrams were drafted, namely: (1) Levels of Centrality/Region of Influence of Nova Friburgo 1966/2007; (2) Urban Hierarchyof Nova Friburgo 1966/2007.
\end{abstract}

Keywords: Urban Network, Levels of Centrality, Region of Influence, Nova Friburgo.

A rede é uma estrutura de interconexão instável, composta de elementos em interação, e cuja variabilidade obedece alguma regra de funcionamento. (...) Esses elementos são os picos ou os

\footnotetext{
${ }^{1}$ Artigo selecionado para apresentação oral no $33^{\circ}$ Congresso da Conferencia Latino-Americana de Geógrafos, realizado entre os dias 26 e 30 de maio de 2015, no Departamento de Geografia da Universidade Federal do Ceará, no Programa de Pós Graduação em Geografia, na cidade de Fortaleza.

${ }^{2}$ Gostaria de externar meus sinceros agradecimentos ao mestrando Daniel Cavalcanti pela elaboração das figuras, além das críticas e sugestões na elaboração do texto final, e à Maria Elaine Andreoti pela revisão final do texto. As imperfeições e opiniões emitidas são de inteira responsabilidade do autor.
} 
nós das redes. (...) A estrutura da rede inclui sua dinâmica. (...) Supõe-se que a variabilidade da estrutura em rede respeita uma norma (...).

(MUSSO apud LIMA, 2010, p. 208).

\section{INTRODUÇÃO}

Este artigo propõe-se a descrever e analisar as áreas de atuação das cidades fluminenses sob a influência de Nova Friburgo, Centro Sub-regional A, município localizado na região de governo Serrana Fluminense. Nos últimos quarenta anos, ocorreram transformações no espaço fluminense que contribuíram sobremaneira para modificar a centralidade e o redimensionamento dos fluxos de deslocamentos, de cidades fluminenses a Nova Friburgo, de consumidores em busca de bens e serviços.

Posto isto, podemos afirmar que a hierarquia e a área de influência dos centros urbanos fluminenses passaram por transformações significativas nesse período analisado, fazendo com que novos centros emergissem, outros perdessem o seu papel e, ainda, que outros se mantivessem na mesma situação. Porém, os resultados aqui apresentados de subordinação sucessiva e de relações de dependência hierárquica entre as cidades fluminenses indicam a crescente diferenciação entre estas e, simultaneamente, a complexidade dessa rede urbana.

A pesquisa fundamenta-se em uma base teórica calcada na teoria das localidades centrais de Walter Christaller (1966) e sua respectiva adaptação a partir de autores como Roberto Lobato Corrêa (1988, 1989, 1993a, 1993b, 1997) e Milton Santos (1979), que lançam ideias críticas e renovadoras sobre a referida teoria.

A escolha do estado do Rio de Janeiro para tratar $\mathrm{r}$ da rede de localidades centrais justifica-se em decorrência das transformações desencadeadas a partir de situações inovadoras que reconfiguraram territorialmente tal espaço, com alterações significativas na dinâmica dos mercados de trabalho locais e mesorregionais e com mudanças nas estratégias dos principais agentes gestores sobre o território governos municipal, estadual e federal e grandes corporações e empresas relacionadas. A questão central a ser desenvolvida é: como, atualmente, encontra-se organizada a rede de distribuição de bens e 
serviços sob a influência de Nova Friburgo, no que diz respeito à hierarquia e centralidade de seus municípios?

Como procedimento operacional, a pesquisa realizada pautou-se na análise da Rede de Distribuição de Bens e Serviços, a partir da metodologia elaborada pela Coordenação de Geografia (CGEO) do IBGE, segundo as obras Divisão do Brasil em Regiões Funcionais Urbanas - 1972 e Regiões de Influência das Cidades - 2007. A partir desta metodologia foram elaborados quadros, mapas e esquemas, a saber: (1) Níveis de Centralidade/Região de Influência de Nova Friburgo 1966/2007; Hierarquia Urbana de Nova Friburgo 1966/2007.

Gostaríamos de esclarecer que a análise da rede de distribuição de bens e serviços, elaborada pela Coordenação de Geografia (CGEO), também realizou pesquisa para os anos de 1987 e 1993. Apesar de termos utilizado para este artigo os recortes temporais de 1966 e 2007, também foi incluído o ano de 1993 para efeitos comparativos.

Para dar conta dos objetivos e do caminho de investigação, o texto foi estruturado em três partes. A primeira busca analisar algumas peculiaridades da Região Serrana Fluminense, onde o município de Nova Friburgo está inserido, e desse município. A segunda refere-se às bases conceituais da pesquisa, tratando das redes geográficas em um primeiro momento e em seguida caracterizando a rede de distribuição difusão como sendo a mais adequada a dos lugares centrais. Por fim, a terceira parte analisa o papel dos centros urbanos na rede de localidades centrais, sua hierarquia e área de influência, a partir do papel de Nova Friburgo, no estado do Rio de Janeiro, comparando dois momentos, 1966 e 2007.

\section{Território fluminense, região serrana e município de Nova Friburgo: importantes laboratórios de pesquisa}


O estudo da rede de localidades centrais torna-se fundamental em decorrência de o estado do Rio de Janeiro ter passado, nos últimos trinta anos, por transformações socioespaciais diversas. Tais transformações, em sua grande maioria, têm como foco de partida a dinâmica da região metropolitana fluminense, comandada pelo seu município-núcleo, o Rio de Janeiro. Entretanto, apesar de pontuais, muitas dessas transformações recentes têm como origem o interior do estado, influenciando na própria rede de distribuição de bens e serviços (RIBEIRO, 2010).

As transformações estariam atreladas à modernização parcial da agricultura; ao aumento da especulação imobiliária; ao crescimento do turismo e da segunda residência (MARAFON et al., 2011; RIBEIRO, COELHO, 2008); à diversificação produtiva em vários setores da economia; à exploração do petróleo na bacia de Campos, no norte fluminense, com o pagamento de royalties às prefeituras municipais, fato que influencia no processo emancipatório de antigas vilas, que se tornam novos municípios; e, por fim, à reestruturação industrial (MARAFON et al., 2011).

Das oito regiões de governo definidas pelo CEPERJ (2014), no tocante à Região Serrana Fluminense, cumpre mencionar que ela é constituída por 14 municípios: Bom Jardim, Cantagalo, Carmo, Cordeiro, Duas Barras, Macuco, Nova Friburgo, Petrópolis, São José do Vale do Rio Preto, São Sebastião do Alto, Santa Maria Madalena, Sumidouro, Teresópolis e Trajano de Morais (mapa1).

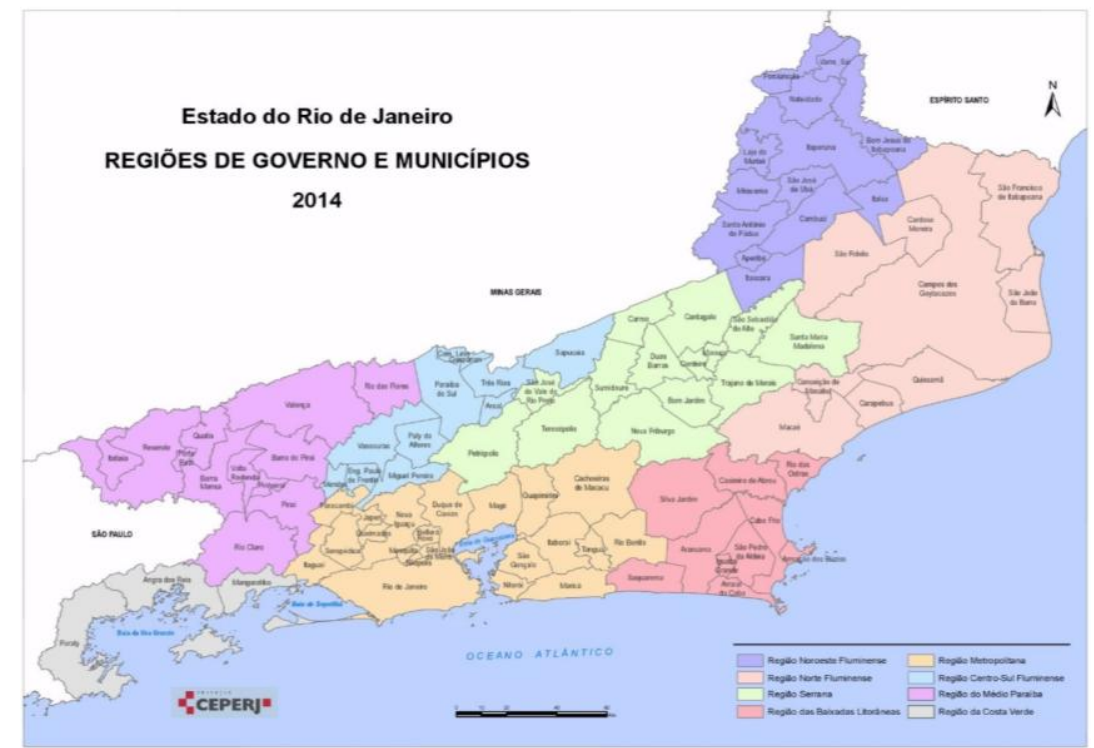

Mapa 1. Regiões de governos e municípios do estado do Rio de Janeiro 
A região apresenta atividades econômicas fundamentadas na produção agrícola, industrial e de serviços, com diferenciações internas bastante significativas, sendo que, para aquele total de 14 municípios, três apresentam desenvolvimento econômico mais expressivo que os demais: Petrópolis, Nova Friburgo e Teresópolis. A região tem por características principais a produção de hortigranjeiros, destinados principalmente ao abastecimento da metrópole, elevados índices de urbanização e uma rede de serviços e infraestrutura suficientes para atender uma economia diversificada. Contudo, as transformações socioespaciais mais recentes têm sido verificadas no meio rural (SEABRA, 2015). Nota-se a expansão tanto de atividades produtivas não agrícolas que visam assegurar mais geração de renda à população, como o turismo e o veraneio, quanto novas atividades agrícolas, como agricultura orgânica, hidropônica, floricultura e cultivo de plantas medicinais, atingindo nichos de mercados importantes no processo de ganhos da produção (MARAFON et al., 2011).

O processo de ocupação da referida região teve sua gênese no fim do século XVIII, com a fixação de "pousos de tropas" que iam em direção às terras auríferas de Cantagalo. No início do século XIX foi ocupada por imigrantes estrangeiros, tais como suíços, alemães, italianos, portugueses e sírios, que se fixaram primeiramente em Nova Friburgo e depois se difundiram por localidades dos atuais municípios de Bom Jardim, Carmo, Cordeiro, Petrópolis e Teresópolis.

Em fins do século XVIII, o café ocupou terras da região serrana e passou a ser a principal atividade produtiva da região, sendo destinado à cidade do Rio de Janeiro para o seu escoamento ao exterior.

A organização espacial das cidades da região surgiu a partir de núcleos agrícolas, nos quais, como dissemos, a agricultura cafeeira teve expressividade. Mas as terras situadas em Petrópolis, Teresópolis e Nova Friburgo, localizadas no alto da serra, não apresentaram relevante produção cafeeira em decorrência do clima e se dedicaram a atividades produtivas vinculadas ao processo de industrialização, no qual o gênero têxtil teve expressivo papel. 
Com o desenvolvimento dos sistemas de engenharia, calcados nas estradas de ferro, a partir da segunda metade do século XIX, as localidades da região passaram a ter maior articulação com a cidade do Rio de Janeiro e outros municípios fluminenses. Mas, a partir de 1960, o sistema ferroviário começou a ser substituído pelas rodovias e, em 1974, com a inauguração da ponte Rio-Niterói, essa mudança infraestrutural foi determinante para o grande fluxo de turistas e veranistas, procedentes principalmente do Rio de Janeiro e de Niterói, permitindo desse modo a complementaridade entre a produção agropecuária e a expansão de pousadas e hotéis-fazenda, incrementando a atividade turística (NATAL, 2003).

Após essas breves considerações referentes à região de governo em que se encontra o município de Nova Friburgo, podemos afirmar que o processo de organização regional que configurou essa região é, em parte, procedente desse município, pois sua história muitas vezes se confunde com a história da Região Serrana, em decorrência de sua importância socioeconômica.

Cumpre mencionar que Nova Friburgo é constituída por oito distritos (PMNF, 2014), a saber: 1Nova Friburgo; $2^{\circ}$ - Riograndina; $3^{0}$ - Campo do Coelho; $4^{\circ}-$ Amparo; $5^{0}$ - Lumiar; $6^{0}$ - Conselheiro Paulino; $7^{0}$ - São Pedro da Serra; $8^{0}$ - Muri (mapa 2).

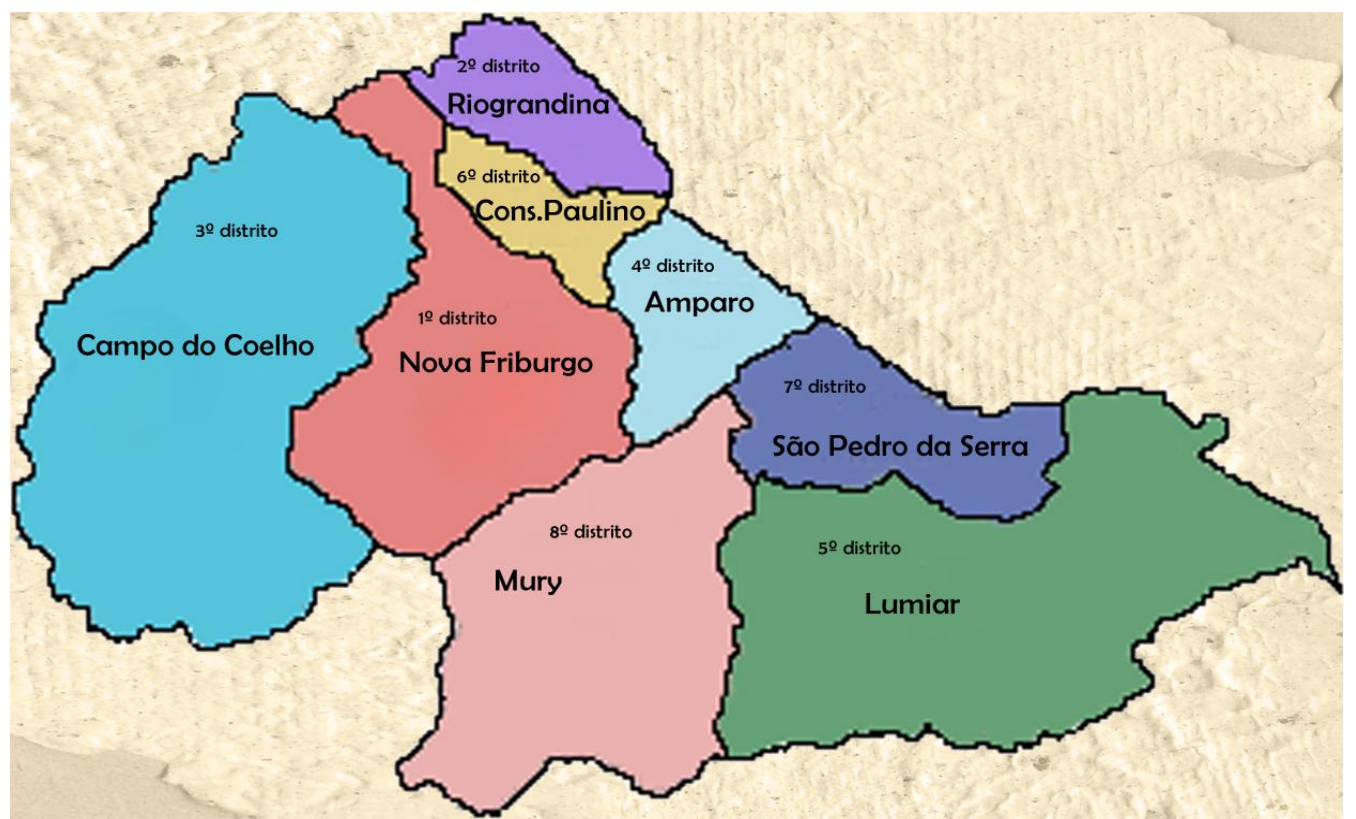

Mapa 2. Distritos do Município de Nova Friburgo. Fonte: Elaborado por Ribeiro e Cavalcanti (2014) segundo IBGE (2014). 
Cumpre fazer referência que foram selecionados alguns indicadores e dados censitários mais recentes, não correspondentes ao último ano da pesquisa REGIC - 2007. Tais informações foram apresentadas com intuito de ratificar a importância e o papel do município de Nova Friburgo na hierarquia de localidades centrais, no contexto fluminense, abordando aspectos econômicos, demográficos e de seus equipamentos urbanos.

O IDHM (Índice de Desenvolvimento Humano Municipal), segundo dados da ONU (2010), foi da ordem de 0,745 , ocupando a $12^{\mathrm{a}}$ posição no estado, sendo bastante expressivo em comparação aos demais 92 municípios fluminenses. Cumpre mencionar que Petrópolis registrou o mesmo índice de Nova Friburgo, ocupando a $13^{\text {a }}$ posição no estado; e Teresópolis, com 0,730, alcançou a $25^{\text {a }}$ posição no estado.

Na tipologia municipal elaborada por Ribeiro e O’Neill, ainda em fase de publicação, segundo o PIB de 2008, Nova Friburgo caracteriza-se fortemente por um centro de serviços, sendo que a distribuição por setores econômicos corresponde a 2,1\% na agropecuária, $13,2 \%$ na indústria e $84,7 \%$ nos serviços. Petrópolis apresenta estrutura econômica diferente do Nova Friburgo, com totais da ordem de $0,2 \%$ para a agropecuária, 30,1\% para o setor industrial e $69,7 \%$ para o setor de serviços, consequentemente complementando atividades de serviços com a atividade industrial, em decorrência do setor de confecções. Já Teresópolis apresenta a mesma dinâmica de Nova Friburgo, registrando os valores de 5,8\% na agropecuária, 13,3\% na indústria e 80,8\% nos serviços.

Em 2010, segundo o Censo Demográfico do IBGE, o município apresentava 182.082 residentes, ocupando a $15^{\mathrm{a}}$ posição quanto ao total de população do estado do Rio de Janeiro e a segunda no contexto da região serrana, somente ultrapassado pelo município de Petrópolis. Desse total, 159.335 residentes estão localizados em áreas urbanas, enquanto 22.681 representam residentes em áreas rurais (RIBEIRO; O'NEILL, 2012), apresentando 87,5\% quanto ao grau de urbanização e acusando uma taxa geométrica de apenas 0,49\% a.a., sendo considerada uma das menores do estado quando comparada a outros municípios fluminenses. 
Sua sede conta com 113.108 residentes, ocupando a $17^{\mathfrak{a}}$ posição entre as maiores cidades fluminenses - de acordo com o IBGE, com população superior a 95.000 habitantes, para o conjunto das 22 maiores cidades fluminenses. Petrópolis ocupa a $11^{\text {a }}$ posição, registrando 185.876 residentes, e Teresópolis, a $16^{\mathrm{a}}$, com 134.045. Essas três cidades, em conjunto, registram 641.865 residentes para um total de 805.803 localizados na região serrana, perfazendo $79,6 \%$ do total das 14 sedes municipais.

O município de Nova Friburgo registra vários equipamentos urbanos que evidenciam sua centralidade, principalmente localizados no perímetro da sede municipal. À guisa de exemplo, podemos apontar, segundo o Portal Cidades do IBGE (2015): 43 estabelecimentos de saúde (SUS); 328 unidades de ensino (infantil, fundamental e médio); 22 agências bancárias; 7.294 empresas atuantes, distribuídas pelos três setores da economia.

Nesse contexto, Nova Friburgo ganha papel de destaque diante dos municípios que estão sob sua influência. São municípios de pouca expressividade populacional, de base agropecuária, que se dirigem a Nova Friburgo à procura de bens e serviços mais complexos, configurando uma sub-rede em território fluminense. Entre os municípios sob sua influência, podemos mencionar três, segundo Farias (2013), que mantêm fluxos pendulares com a sede municipal em 2010. São eles: Sumidouro, Duas Barras e Bom Jardim, que expressam essa pendularidade para trabalho, estudo e lazer, entre outros.

As características apresentadas, de ordem histórica, demográfica e econômica, provocaram alterações no papel dos centros e de suas centralidades, evidenciando a importância de Nova Friburgo como centro de ressonância regional. Antes de analisar o seu papel na rede de localidades centrais fluminense, a parte seguinte apresentará os fundamentos conceituais propostos para este artigo.

\section{As bases conceituais: as redes geográficas}

De modo sucinto, pode-se estabelecer um conceito inicial para redes a partir de Kansky, citado por Bakis (1993) e Corrêa (1997). Considera-se uma rede como "um conjunto de localizações geográficas 
interconectadas entre si por um certo número de ligações". Para Santos (1994, p. 167), as redes se originam de fixos e fluxos. Os elementos fixos, nesse caso os nós na rede, são representados pelos centros urbanos (cidades), constituídos como resultado do trabalho social; e os fluxos (caminhos, deslocamentos) garantem as interações (relacionamentos) entre os fixos. Isto configura uma rede urbana. Ela é uma rede geográfica, na qual os nós desempenham múltiplos papéis.

Para a pesquisa em tela será enfatizada a rede de distribuição de bens e serviços (difusão), sendo a mais adequada a dos lugares centrais, objeto de nosso estudo (RIBEIRO, 1998).

Os lugares centrais, segundo suas hierarquias, permitem oferecer os bens e serviços em função das necessidades. As necessidades elementares e frequentes não necessitam de um deslocamento importante, considerando-se um raio de 100 a 200 metros. As necessidades sofisticadas e muito raras podem ser satisfeitas por um lugar central, num raio de milhares de quilômetros (MIOSSEC, 1976).

Esse tipo de interação está fundamentado nos pressupostos concebidos pela teoria dos lugares centrais, formulada por Walter Christaller em 1933, tendo como base a centralidade e a região de influência. 0 estudo da hierarquia das cidades está pautado em questionamentos sobre número, tamanho e distribuição das cidades e, consequentemente, estabelecendo a diferenciação entre elas.

A natureza da rede urbana, no tocante à rede de distribuição, é compreendida através da hierarquia de seus centros, isto é, a posição que estes ocupam no conjunto de centros, dados em decorrência da oferta de bens e serviços, caracterizando-os como uma localidade central; ou seja, o próprio centro é dotado de uma centralidade.

Segundo Corrêa (1989, p. 20-21), o interesse em se estudar a temática da hierarquia urbana decorre de que

com o capitalismo, o processo de diferenciação das cidades se acentua, aí incluindo-se a hierarquização urbana: a criação de um mercado consumidor, a partir da expropriação dos meios 
de produção e de vida de enorme parcela da população, e a industrialização levam à expansão da oferta de produtos industriais e de serviços. Esta oferta, por sua vez, se verifica de modo espacialmente desigual, instaurando-se então a hierarquia das cidades. Esta, por sua vez, suscita ações desiguais por parte dos capitalistas e do Estado: daí o interesse em compreender a sua natureza.

A importância desses núcleos e o que os distinguem dos demais é a sua centralidade, expressa pelo grau de importância a partir de suas funções centrais, ou seja, a oferta de bens e serviços. Quanto maior o número de bens e serviços oferecidos (funções centrais), maior será o grau de centralidade, como também a sua região complementar (área de mercado), além da maior quantidade de população externa atendida.

O arranjo espacial da rede de centros é influenciado pelo modo como se verifica a distribuição espacial da produção e da população, que é influenciada pelas condições naturais específicas e pelo modo como foram e são avaliadas e utilizadas pelo homem. É influenciada também pela acumulação de arranjos espaciais pretéritos dos centros urbanos e pelas novas localizações que emergem no presente. As possibilidades de arranjos espaciais das redes de localidades centrais tornam-se, então, variadíssimas.

A centralidade decorre da ação de dois mecanismos econômicos: (a) mercado mínimo (threshold), ou seja, o número mínimo de população a ser servida, que implica a oferta, por parte das empresasdos centros, de maior ou menor variedade e quantidade de bens e serviços; (b) alcance espacial (range), ou seja, o limite territorial da distribuição de bens e serviços por parte das firmas dos centros. Tais mecanismos têm suas raízes na variabilidade da frequência de consumo de uma gama diversificada de bens e serviços e caracterizam-se por variações em função das densidades demográficas, padrões culturais, renda da população e acessibilidade aos centros.

O seguinte esquema geral deve ser retido: (i) os pequenos centros distribuem bens e serviços pouco diversificados e de consumo frequente para um número pequeno de população que se localiza dentro de um pequeno raio dos centros (as firmas desses centros operam sob condições de baixo mercado mínimo 
e alcance espacial); (ii) os grandes centros distribuem bens e serviços bastante diversificados, de consumo frequente, pouco frequente e ocasional para um número grande de população que se localiza dentro de amplo raio dos centros (as firmas desses centros operam sob condições de baixo, médio e amplo mercado mínimo e alcance espacial); (iii) há uma hierarquia de centros e de regiões de influência urbana, na qual temos um centro maior, alguns poucos centros grandes, vários centros médios e numerosos centros pequenos. A literatura sobre o assunto refere-se a "centro metropolitano", "capital regional", "centro sub-regional", "centro de zona" e "centro local".

Segundo a teoria das localidades centrais, o centro de nível hierárquico mais elevado (metrópole regional) é dotado de uma maior área de influência, onde estaria contida a própria região de influência do centro de patamar imediatamente inferior ao seu (capital regional). Assim, fica desenhada uma hierarquia na qual, de forma sistemática, os patamares mais baixos são englobados pelos de níveis imediatamente superiores.

A conclusão acima induz a dois outros aspectos sobre a natureza da hierarquia urbana. 0 primeiro deles é que, quanto maior for o nível hierárquico de um centro, mais distanciado ele estará de outro de mesmo nível e, portanto, menor será a quantidade de centros de mesmo patamar. Além disso, quanto maior o nível hierárquico do centro, maior será sua área de influência e maior será a população por ele atendida em suas necessidades de consumo de bens e serviços. $\mathrm{O}$ segundo aspecto diz respeito à relação entre o nível hierárquico e as funções urbanas: a oferta das últimas é maior quanto mais alta for a hierarquia do centro, possibilitando neste a existência de população maior e de um maior número de empregos.

Esses pressupostos da teoria das localidades centrais, na atualidade, não apresentam estrutura rígida, pois existem centros especializados de patamar populacional nem sempre correspondente às mais altas hierarquias na rede urbana; a importância do número de procuras de municípios por um determinado centro, denotando sua maior centralidade na rede; além dos sistemas de engenharia, que contribuíram para aumentar a mobilidade da população em seus deslocamentos, caso das rodovias e do sistema 
aéreo, juntamente com a ampliação dos sistemas de informação, permite uma maior rapidez nos deslocamentos e no acesso às informações (RIBEIRO, 2010).

\section{O papel dos centros urbanos na rede de localidades centrais de Nova Friburgo}

Neste tópico, procuramos analisar primeiramente a hierarquia e as áreas de influência de Nova Friburgo no estado do Rio de Janeiro e na região serrana, a partir dos quadros para os anos de 1966 (primeira pesquisa) e 2007 (última pesquisa realizada pela coordenação de geografia do IBGE, alicerçada na procura e oferta dos municípios por bens e serviços).

Esclarecemos que a análise da rede de distribuição de bens e serviços elaborada pela Coordenação de Geografia (CGEO) também realizou pesquisa para os anos de 1987 e 1993, optando-se, para essa análise, pelos dois recortes temporais selecionados.

No mapa 3 a seguir, estão representadas a centralidade dos centros urbanos fluminenses.

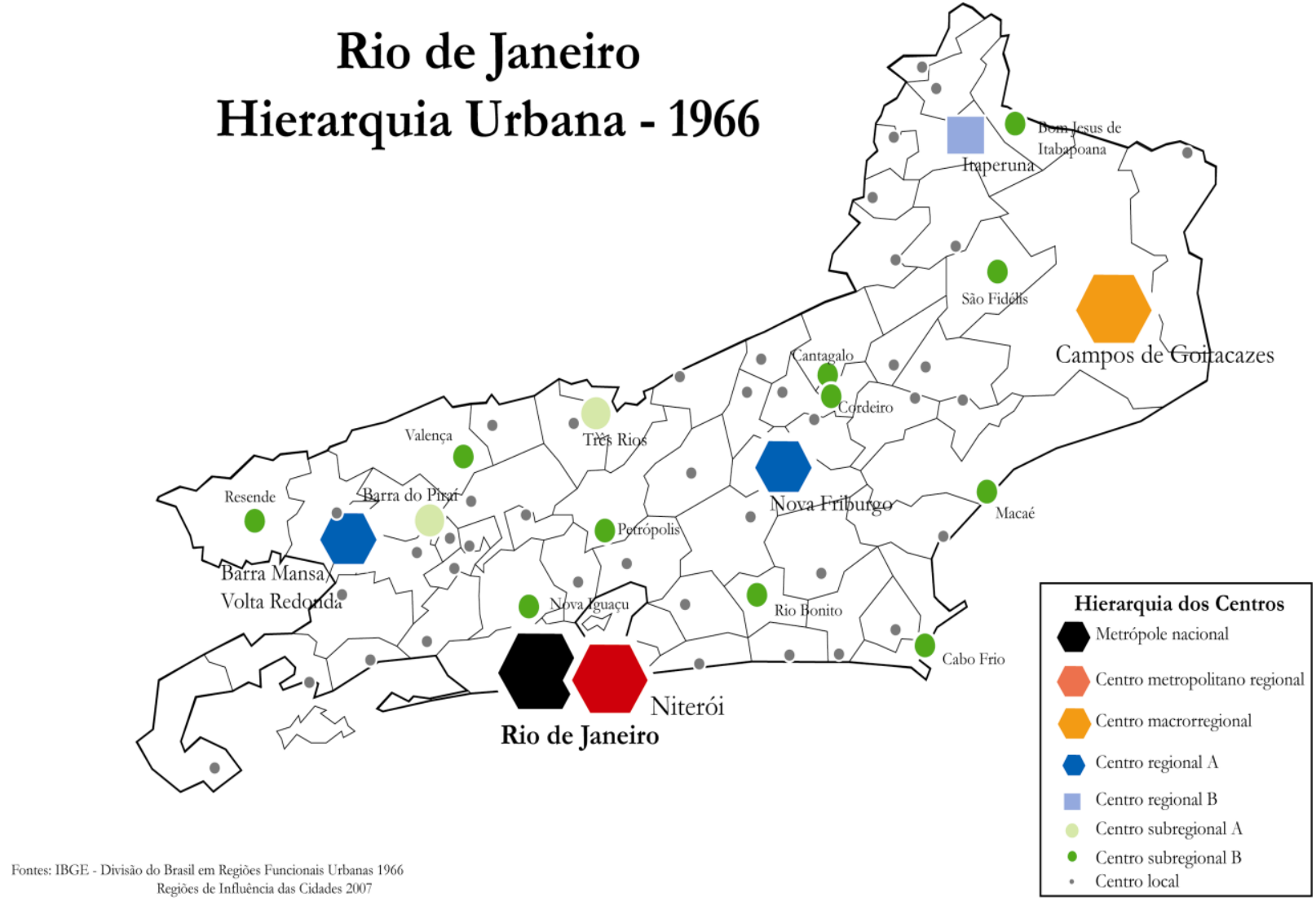

Mapa 3. Distritos do Município de Nova Friburgo. Fonte: Elaborado por Ribeiro e Cavalcanti (2014) segundo IBGE (2014). 
19660 quadro 1 identifica a hierarquia e áreas de influência no estado do Rio de Janeiro, destacandose uma metrópole nacional, a capital do Rio de Janeiro; quatro centros regionais: Juiz de Fora (MG), Vitória (ES), Campos dos Goytacazes e Niterói (RJ); três centros sub-regionais: Barra Mansa/Volta Redonda, Nova Friburgo e Itaperuna; treze centros locais, incluindo Macaé e vários municípios subordinados. Nessa escala, Nova Friburgo cumpre o papel de centro sub-regional de nível 3a

De modo geral, os agricultores familiares acionam diversas estratégias que têm viabilizado a reprodução social e a permanência do grupo no meio rural. Entende-se que as estratégias são definidas como um conjunto de ações racionais, resultantes de escolhas, opções e decisões dos indivíduos.

\begin{tabular}{|c|c|}
\hline $\begin{array}{l}\text { Metrópole } \\
\text { nacional }\end{array}$ & Nível 1b: Rio de Janeiro \\
\hline Centro regional & $\begin{array}{l}\text { Nível 2a: Juiz de Fora (MG); Vitória (ES) } \\
\text { Nível 2b: Campos dos Goytacazes; Niterói }\end{array}$ \\
\hline $\begin{array}{l}\text { Centro sub- } \\
\text { regional }\end{array}$ & $\begin{array}{l}\text { Nível 3a: Barra Mansa/Volta Redonda; Nova Friburgo } \\
\text { Nível 3b: Itaperuna }\end{array}$ \\
\hline Centro local & $\begin{array}{l}\text { Nível 4a: Três Rios; Barra do Piraí } \\
\text { Nível 4b: Nova Iguaçu; Petrópolis; Resende; Valença; Macaé; São Fidélis; Bom Jesus do } \\
\text { Itabapoana; Cabo Frio; Rio Bonito; Cantagalo; Cordeiro }\end{array}$ \\
\hline $\begin{array}{l}\text { Municípios } \\
\text { subordinados }\end{array}$ & $\begin{array}{l}\text { Angra dos Reis, Duque de Caxias, Itaguaí, Magé, Mangaratiba, São João de Meriti, Nilópolis, Paracambi, } \\
\text { Paraíba do Sul*, Sapucaia, Rio Claro, Engenheiro Paulo de Frontin, Mendes, Miguel Pereira, Piraí, } \\
\text { Vassouras, Rio das Flores, Itaocara, Miracema, São João da Barra, Santa Maria Madalena*, Santo } \\
\text { Antonio de Pádua, São Sebastião do Alto, Casimiro de Abreu*, Conceição de Macabu, Trajano de } \\
\text { Morais*, Cambuci*, Laje de Muriaé, Natividade, Porciúncula, Cachoeiras de Macacu, Itaboraí, Maricá, } \\
\text { São Gonçalo, Saquarema, São Pedro da Aldeia, Araruama, Silva Jardim, Bom Jardim, Carmo, } \\
\text { Sumidouro, Duas Barras }\end{array}$ \\
\hline
\end{tabular}

Quadro 1. Divisão do Brasil em Regiões Funcionais Urbanas - 1966 (1972) - estado do Rio de Janeiro. * Ligase a dois centros de hierarquia imediatamente superior ou a um centro de hierarquia imediatamente superior situado fora da região funcional urbana de nível mais alto a que pertence o município.Fonte: Elaborado por RIBEIRO a partir das informações do IBGE, REGIC, 1972. 
Para 2007 (mapa 4 e quadro 2), podemos observar que há uma alteração na hierarquia no contexto fluminense, no qual Nova Friburgo passa a exercer o papel de centro sub-regional A, juntamente com Cabo Frio, Itaperuna e Macaé. Convém mencionar que, nesse momento, existiam quatro centros exercendo o papel de capital regional em três níveis, sendo dois centros correspondentes a Vitória (ES), capital regional de nível A, e Juiz de Fora (MG), exercendo papel de capital regional de nível B. Nesse caso, esses dois centros exercem papel de nível mais elevado nas cidades fluminenses, estando sob a influência direta do Rio de Janeiro - metrópole nacional.

Como capital regional C destacam-se Campos dos Goytacazes, na região de governo norte fluminense, e Volta Redonda/Barra Mansa, na região do médio Vale do Paraíba, exercendo, em 2007, a maior centralidade entre as cidades fluminenses.

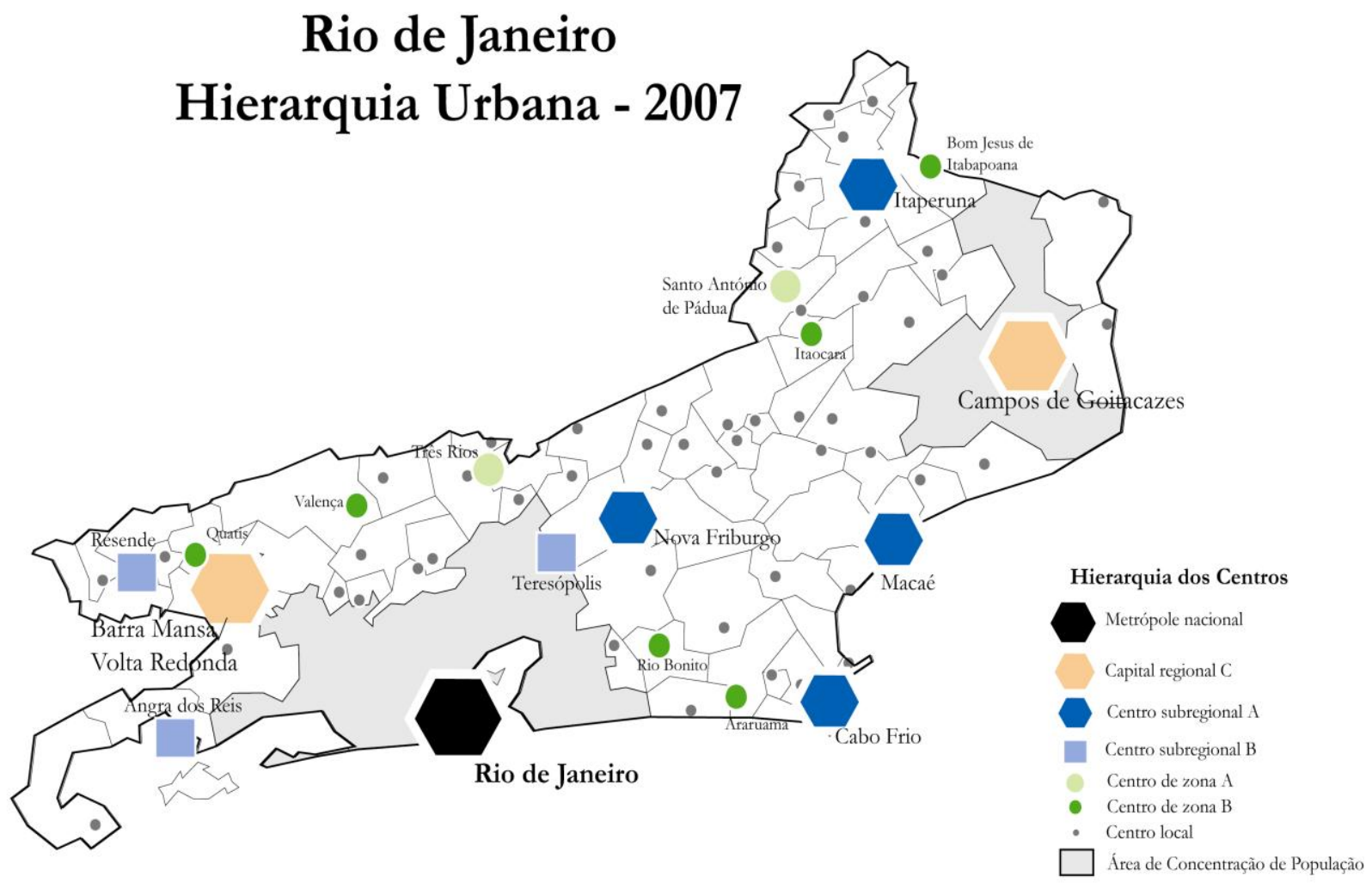

Mapa 4. Rio de Janeiro Hierarquia Urbana - 2007 


\begin{tabular}{|c|c|}
\hline nacional & \\
\hline $\begin{array}{c}\text { Capital } \\
\text { regional A }\end{array}$ & Vitória (ES) \\
\hline $\begin{array}{c}\text { Capital } \\
\text { regional B }\end{array}$ & Juiz de Fora (MG) \\
\hline $\begin{array}{c}\text { Capital } \\
\text { regional C }\end{array}$ & Campos dos Goytacazes - Volta Redonda/Barra Mansa \\
\hline $\begin{array}{l}\text { Centro sub- } \\
\text { regional A }\end{array}$ & Cabo Frio - Itaperuna - Macaé - Nova Friburgo \\
\hline $\begin{array}{l}\text { Centro sub- } \\
\text { regional B }\end{array}$ & Angra dos Reis - Teresópolis - Resende \\
\hline $\begin{array}{c}\text { Centro de } \\
\text { zona A }\end{array}$ & Três Rios - Carangola (MG) - Santo Antônio de Pádua - Além Paraíba (MG) \\
\hline $\begin{array}{c}\text { Centro de } \\
\text { zona B }\end{array}$ & Araruama - Rio Bonito - Valença - Bom Jesus do Itabapoana - Itaocara - Quatis \\
\hline Centro local & $\begin{array}{l}\text { Areal, Cachoeiras de Macacu, Carmo*, Casimiro de Abreu, Miguel Pereira, Paty do Alferes, Saquarema, } \\
\text { Tanguá, Vassouras, Iguaba Grande*, Silva Jardim, Rio Preto (MG)*, Rio das Flores, Chiador (MG), } \\
\text { Comendador Levy Gasparian, Paraíba do Sul, Sapucaia, Parati, São José do Vale do Rio Preto, Armação dos } \\
\text { Búzios, Arraial do Cabo, São Pedro da Aldeia, São José do Calçado (ES), Laje do Muriaé, Miracema*, } \\
\text { Natividade, Porciúncula, São José de Ubá, Varre-Sai, Apiacá (ES), Aperibé, Cambuci, Carapebus, Conceição } \\
\text { de Macabu, Rio das Ostras, Bom Jardim, Cantagalo, Cordeiro, Duas Barras, Macuco, Santa Maria Madalena, } \\
\text { São Sebastião do Alto, Sumidouro, Trajano de Morais, Bom Jesus do Norte (ES)*, Cardoso Moreira, Italva, } \\
\text { Quissamã, São Francisco de Itabapoana, São Fidélis, São João da Barra, Pirapetinga (MG)*, Santa Rita de } \\
\text { Jacutinga (MG), Engenheiro Paulo de Frontin, Mendes, Rio Claro, Bananal (SP), Passa-Vinte (MG), } \\
\text { Itatiaia, Porto Real, Arapeí (SP) }\end{array}$ \\
\hline
\end{tabular}

Quadro 2. Regiões de Influência das Cidades - 2007 (2008) - região de influência do Rio de Janeiro. * Centros com múltiplas vinculações.Fonte: Quadro elaborado por RIBEIRO, a partir das informações do IBGE, REGIC, 2008.

Quanto à análise dos níveis de centralidade e da região de influência de Nova Friburgo, comparando os dois recortes temporais, registra-se para o primeiro momento a centralidade friburguense como centro sub-regional de nível 3a, sob a influência direta de Niterói, que naquele momento exercia a função de capital do antigo estado do Rio de Janeiro. A capital fluminense estava diretamente vinculada à capital 
estadual do antigo estado da Guanabara, a cidade do Rio de Janeiro, metrópole nacional, conforme pode ser observado na figura 1.

Cumpre lembrar que desde 1960 a cidade do Rio de Janeiro perdeu sua capitalidade em nível federal, como apontou Lessa (2000), para Brasília, tornando-se cidade/estado, sediando a capital deste - o antigo estado da Guanabara, exercendo papel primordial de metrópole nacional, comandando diretamente alguns municípios fluminenses em sua área imediata, como também dois municípios localizados em outras unidades federadas.

No exemplo de Nova Friburgo, o referido município encontra-se na área de influência imediata de Niterói, centro regional de nível $2 \mathrm{~b}$. Tal situação tem como fator marcante a acessibilidade, pois o centro friburguense tinha acesso dificultado à antiga capital federal- e, consequentemente, seus vínculos se faziam com maior intensidade com a antiga capital fluminense, Niterói. Sua área de influência direta contemplava cinco municípios, sendo que um também apresentava ligação com Campos dos Goytacazes (Santa Maria Madalena) e outro com Macaé (Trajano de Morais). Consequentemente, Nova Friburgo repartia sua centralidade com os dois municípios mencionados.

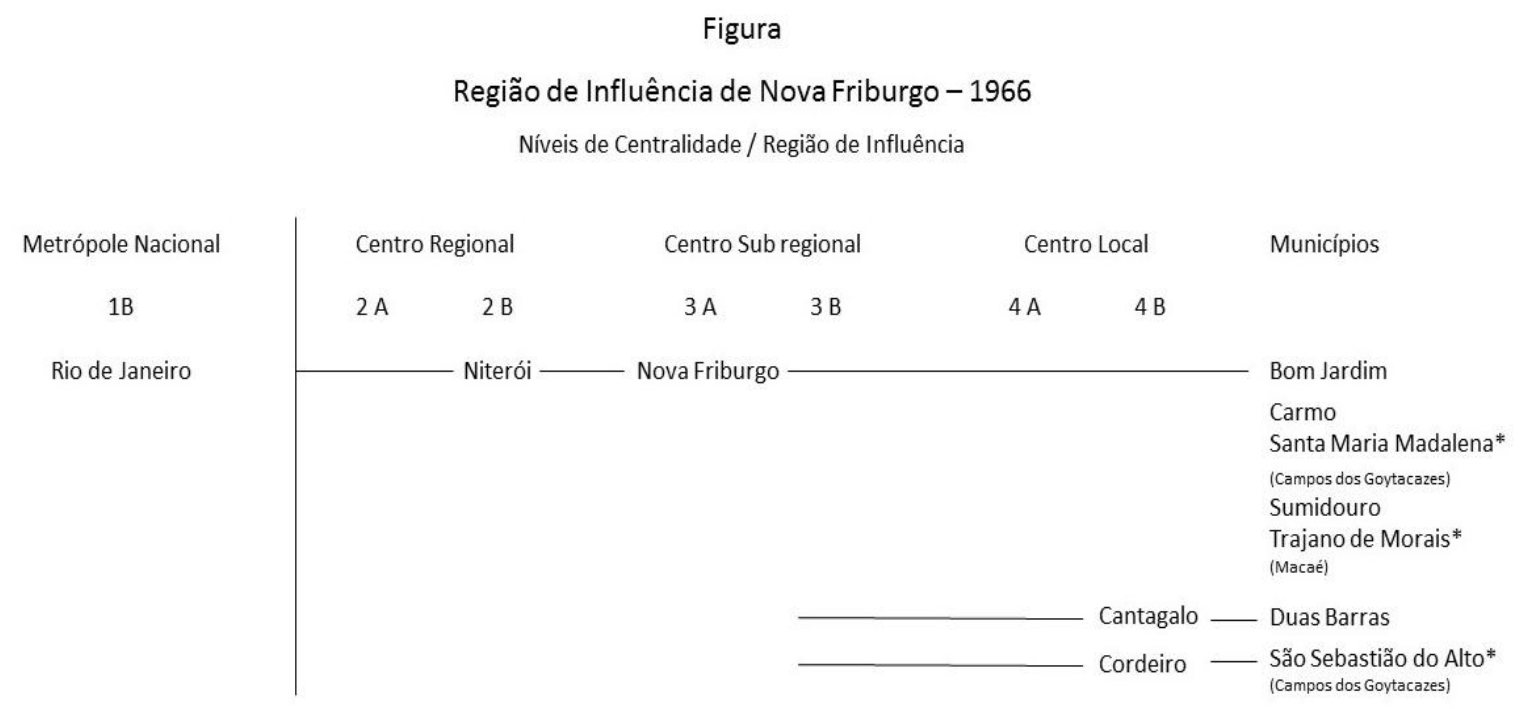

Fonte: IBGE. Divisão do Brasil em Regiões Funcionais Urbanas. 1972

Figura 1. Região de Influência de Nova Friburgo - 1966 
Outros dois centros, Cantagalo e Cordeiro, classificados como centros locais de nível 4b, pertenciam a essa região de influência, estando diretamente subordinados a Nova Friburgo. Estes apresentavam em sua área de influência direta um município cada, como pode ser observado na figura 1.

Em 2007, a Coordenação de Geografia realizou sua última pesquisa empregando uma metodologia diferente daquela elaborada em 1966, na qual Nova Friburgo passa a exercer o papel de centro subregional de nível A, estando diretamente vinculado à metrópole nacional do Rio de Janeiro. Em sua área de influência direta aparecem nove municípios caracterizados como centros locais, como pode ser observado na figura 2. Dentre esses municípios, como comentado anteriormente, três apresentam deslocamentos diários com Nova Friburgo no ano de 2010: Sumidouro, Duas Barras e Bom Jardim (FARIAS, 2013)

Figura

Região de Influência de Nova Friburgo - 2007

Níveis de Centralidade / Região de Influência

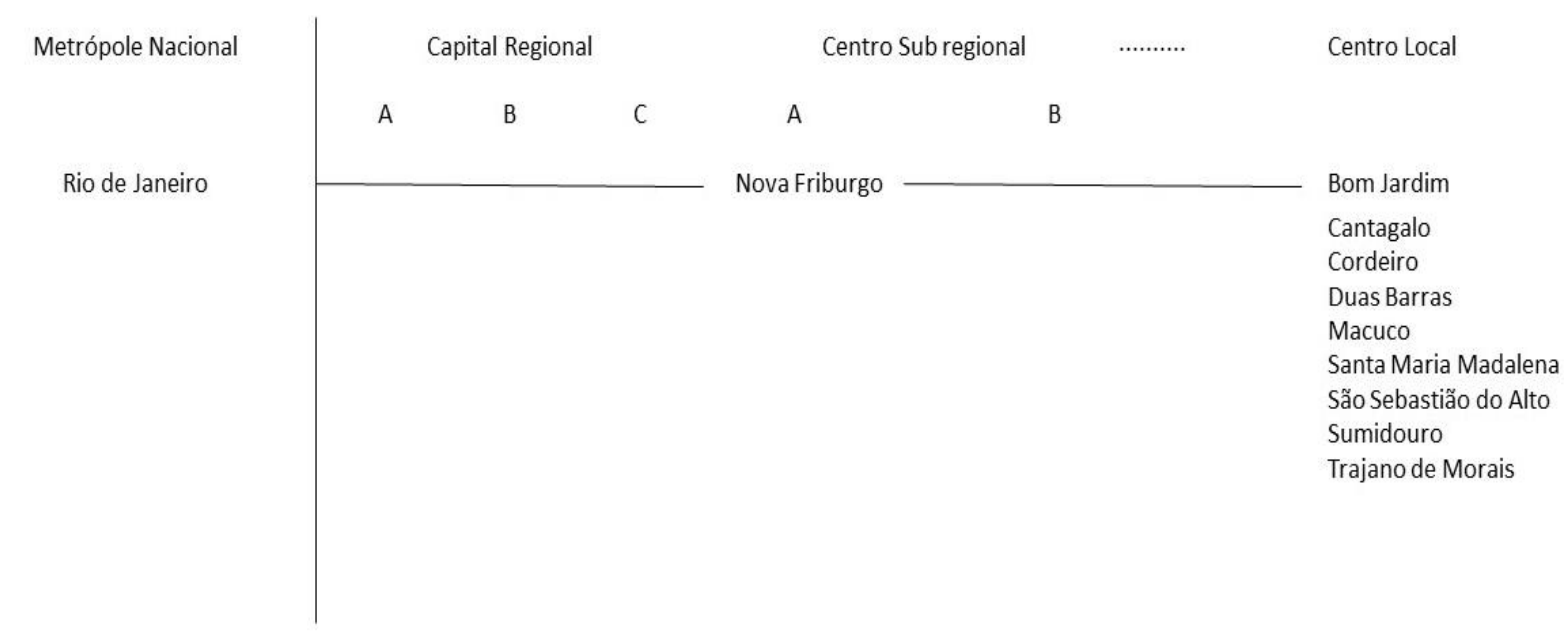

Fonte: IBGE. Regiões de Influência das Cidades. 2007.

Figura 2. Região de Influência de Nova Friburgo - 2007

Cumpre mencionar que Nova Friburgo, no contexto da Região Serrana Fluminense, apresenta maior centralidade diante dos demais municípios da região, fato que pode ser explicado pela sua acessibilidade à metrópole do Rio de Janeiro, diante de Petrópolis, que atualmente encontra-se 
diretamente na área de abrangência desta metrópole, e Teresópolis, que apresenta patamar hierárquico inferior a Nova Friburgo, como pode ser observado no quadro 2.

Para ilustrar e ratificar as relações de Nova Friburgo com os municípios que integram sua área de influência, recorremos ao trabalho de Farias (2013), que elabora uma tipologia dos movimentos pendulares d e população para o território fluminense em 2010 que indicam tais movimentos no recorte espacial selecionado neste estudo. Esses fluxos pendulares coincidem com parte da área de influência de Nova Friburgo na rede de localidades centrais, conforme mencionado anteriormente.

Em março de 2015, o IBGE publicou, pela Coordenação de Geografia, a obra Arranjos populacionais e concentrações urbanas do Brasil. Ainda que Nova Friburgo não esteja incluída nesse conjunto de concentrações urbanas, em decorrência dos critérios adotados para a formação destes, poderíamos afirmar que a área imediata deste centro sub-regional, juntamente com Sumidouro, Duas Barras e Bom Jardim, poderia ser considerada um arranjo populacional no contexto fluminense, pois, segundo a referida obra: "um arranjo populacional é o agrupamento de dois ou mais municípios onde há uma forte integração populacional devido aos movimentos pendulares para trabalho ou estudo, ou devido à contiguidade entre as manchas urbanizadas principais" (IBGE, 2015, p. 22).

\section{CONSIDERAÇÕES FINAIS}

Para concluir, podemos afirmar que Nova Friburgo, no contexto da rede de localidades centrais fluminense, alterou sua dinâmica nesses mais de quarenta anos, apresentando transformações significativas em sua posição na oferta de bens e serviços e passando a ocupar um papel de centralidade expressivo no contexto do estado do Rio de Janeiro e em parte da Região Serrana Fluminense. Tais transformações são decorrentes:

1. da acessibilidade, representada principalmente pela rede rodoviária, complementada hoje, secundariamente, pelo transporte aéreo, havendo uma diversificação e expansão da circulação; 
2. do aprofundamento da divisão social e territorial do trabalho;

3. do aumento populacional e do mercado consumidor.

Nesse contexto, se compararmos os dois anos selecionados para a análise, podemos afirmar que a área de influência de Nova Friburgo sofre modificações. De uma rede mais estruturada em 1966, com vários centros sob sua influência direta (figura 1), e dois centros locais, em 2007 passou a comandar uma área de influência de pouca complexidade, com nove centros locais vinculados diretamente ao referido município.

Esta situação verificada pode ser explicada por vários fatores, dentre eles dois fundamentais: com a ampliação do sistema de engenharia e da divisão territorial do trabalho, a tendência foi de novos centros exercerem papel hierárquico maior na rede fluminense, diminuindo consequentemente suas áreas de influência, podendo-se exemplificar com Itaperuna, município localizado na Região de Governo Noroeste Fluminense, próximo a Nova Friburgo; os centros de maior hierarquia, como Nova Friburgo, comandam centros menores em tamanho populacional, de pouca expressividade no tocante às atividades econômicas, com consumo baixo de bens e serviços de seus residentes, além de apresentarem deslocamentos de menor distância. Nesse sentido, diversas sub-redes surgem nos níveis de maior hierarquia, tais como: capital regional C; centro sub-regional A e B e centro de zona A e B, comandando vários centros locais.

Isto posto, o resgate da dimensão urbana no território fluminense a partir da análise da rede de distribuição de bens e serviços - localidades centrais - se justifica em decorrência de sua relevância para a geografia. Através dela é possível determinar as diferentes escalas da divisão territorial do trabalho e a complexidade da rede urbana, dado o papel específico e hierarquizado de cada lugar nos fluxos que compõem esse tipo de rede.

Para finalizar, podemos concluir afirmando: 
A recuperação da teoria das localidades centrais é importante porque ela trata de um tema relevante que é o de organização espacial da distribuição de bens e serviços, portanto, de um aspecto da produção e de sua projeção espacial, sendo assim, uma faceta da totalidade social. Recuperá-la porque se torna necessário enriquecer a visão geográfica da sociedade, isto é, enriquecer nossa compreensão sobre as diferentes formas de espacialização da sociedade. (CORRÊA, 1997, p. 17)

\section{REFERÊNCIAS}

BAKIS, Henry. Les Réseaux et leurs sociaux. Que sais-je? Presses. Paris: Universitaires de France, 1993.127 p

BRASIL. IBGE. Divisão do Brasil em regiões funcionais urbanas. Rio de Janeiro, 1972. 112 p.

BRASIL. IBGE. Regiões de influência das cidades. Rio de Janeiro, 1987. 212 p.

BRASIL. IBGE. Regiões de influência das cidades - 1993. Rio de Janeiro, 2000. 230 p.

BRASIL. IBGE. Regiões de Influência das Cidades. Rio de Janeiro, 2007. 202 p.

BRASIL. IBGE. Censo Demográfico. Rio de Janeiro, 2010.

BRASIL. IBGE. Arranjos Populacionais e Concentrações Urbanas do Brasil. Coordenação de Geografia, Rio de Janeiro: IBGE, 2015. 170 p.

CHRISTALLER, Walter. Central places in Southern Germany. Trad. Die Zentralen Orte Süddeutschland by Carlisle W. Baskin. New Jersey: Prentice-Hall, INC. Englewood Cliffs, 1996.

CORREAA, Roberto Lobato. O estudo da rede urbana: uma proposição metodológica. In: Revista Brasileira de Geografia. Rio de Janeiro: IBGE, 50 (2): p. 107-124, abr.-jun. 1988.

A rede urbana. São Paulo: Ática, 1989. 96 p.

. Redes, fluxos e territórios: uma introdução. In: Anais - III Simpósio Nacional de Geografia Urbana. Rio de Janeiro: AGB, set. 1993a. p. 31-32.

Origem e tendências da rede urbana brasileira: algumas notas. Rio de Janeiro: IBGE, 1993b. 10 p.

As Redes Geográficas. In: Trajetórias Geográficas. Rio de Janeiro: Bertrand Brasil, 1997. 304 p.

Região de influência das Cidades. 19 p. (mimeo)

FARIAS, Luiz Antônio Chaves de. Trajetórias Recentes da Pendularidade na Rede Urbana Fluminense. Monografia (Aperfeiçoamento/Especialização em Geografia) - Universidade do Estado do Rio de Janeiro, 2013.

LESSA, Carlos. 0 Rio de todos os brasis: uma reflexão em busca da autoestima. Rio de Janeiro/São Paulo: Record, 2000. 
LIMA, Ivaldo Gonçalves de. A complexidade das redes políticas. In SILVA, Carlos Alberto Franco da et al. (orgs.). As redes políticas do agronegócio da soja: interesses, estratégias e resistências. Rio de Janeiro: Livre Expressão, p. 201-215, 2010.

MARAFON, Glaucio José; RIBEIRO, Miguel Angelo.; CORRÊA, Renata da Silva; VASCONCELOS, Vinícius Neves. Geografia do Estado do Rio de Janeiro: da compreensão do passado aos desafios do presente. $1^{\text {a }}$ ed. Rio de Janeiro: Gramma, 2011. v. 1. 161 p.

MIOSSEC, Jean-Marie. La localisation des forces de décision dans le monde: esquisse de geographié. Paris: Doin Éditeurs, 1976, n. 3. p. 165-175.

NATAL, Caroline Bezerra. "O turismo rural na região serrana fluminense: um estudo de caso - São Pedro da Serra". In:

MARAFON, Glaucio José; RIBEIRO, Miguel Angelo (orgs.). Revisitando o território fluminense II. Rio de Janeiro: NEGEF, 2003, p. 169-185.

ONU. Programa das Nações Unidas para o Desenvolvimento, 2010.

RIBEIRO, Miguel Angelo. A complexidade da rede urbana amazônica: três dimensões de análise. Tese (doutorado em Geografia) - Universidade Federal do Rio de Janeiro: 1998. 335 p.

Os centros urbanos na rede de localidades centrais: o norte fluminense em questão. In: SANTOS, Angela Moulin S. Penalva et al. (org.). Rio de Janeiro: um olhar socioespacial. Rio de Janeiro: Gramma, 2010, p. 243-257.

; COELHO, Maria do Socorro Alves. A importância do fenômeno de segunda habitação e suas implicações com a atividade de lazer-veraneio: o exemplo do estado do Rio de Janeiro. In: MARAFON, Glaucio José; PESSOA, Vera Lúcia Salazar. Agricultura, desenvolvimento e transformações socioespaciais: reflexões interinstitucionais e constituição de grupos de pesquisa no rural e no urbano. Uberlândia: Assis Editora, 2008.

; O’NEIL, Maria Mônica V. C. Considerações sobre a Dinâmica Populacional Fluminense: contrastes entre a metrópole e o interior. In: MARAFON, Glaucio José; RIBEIRO, Miguel Angelo (org.). Revisitando o Território Fluminense IV. $1^{\text {a }}$ ed. Rio de Janeiro: Gramma, 2012, v. 1, p. 199-228.

Análise da tipologia municipal segundo o PIB 2008 para municípios fluminenses. (mimeo).

SANTOS, Milton. Uma revisão da teoria dos lugares centrais. In: Economia espacial críticas e alternativas. São Paulo: Ed. Hucitec, 1979. p. 101-109.

Téenica Espaço Tempo. Globalização e meio técnico-científico informacional. São Paulo: Editora Hucitec, 1994. 190 p.

SEABRA, Rogério dos Santos. A Rede de comercialização agrícola no Estado do Rio de Janeiro: articulações, processos e fluxos nas novas formas de abastecimento familiar. Tese (doutorado) -Universidade do Estado do Rio de Janeiro: 2015.

\section{SITES}

BRASIL, IBGE. Cidades@. Disponível em: <www.ibge.gov.br/cidadesat>. Acesso em: 29/03/2014. 